\title{
Mechanical properties of a baseline UHPC with and without steel fibers
}

\author{
E. M. Williams, S. S. Graham, S. A. Akers, P. A. Reed \\ \& T. S. Rushing \\ US Army Engineer Research and Development Center, \\ Geotechnical and Structures Laboratory, USA
}

\begin{abstract}
Personnel of the Geotechnical and Structures Laboratory, US Army Engineer Research and Development Center, conducted a series of laboratory experiments to investigate the strength and constitutive property behavior of baseline ultrahigh-performance composite concrete (Cor-Tuf) with and without steel fibers. A total of 23 mechanical property tests were successfully completed for each Cor-Tuf concrete. The property tests included hydrostatic compression, unconfined compression (UC), triaxial compression (TXC), unconfined direct pull (DP), uniaxial strain, and uniaxial-strain-load/constant-volume-strain loading tests. Results of the TXC tests exhibited a continuous increase in maximum principal stress difference with increasing confining stress. A compression failure surface was developed from the TXC and the UC test results. The results for the DP tests were used to determine the unconfined tensile strength of the concretes, which was less than $10 \%$ of the unconfined compression strength. The Cor-Tuf with the steel fibers exhibits slightly greater strength with increased confining pressure than the Cor-Tuf without steel fibers. Overall, the results from all of the compression tests for both Cor-Tuf concretes were very similar.
\end{abstract}

Keywords: ultra-high-performance concrete, steel fibers, high pressure mechanical response.

\section{Introduction}

Cor-Tuf is the nomenclature given to a family of ultra-high-performance concretes (UHPCs) developed at the Geotechnical and Structures Laboratory 
(GSL), U.S. Army Engineer Research and Development Center (ERDC). UHPCs are distinguished by their high compressive strengths (ranging from 190 to $244 \mathrm{MPa}$ in the case of the Cor-Tuf cylinders). The Cor-Tuf concrete composition was designed to develop ultra high compressive strength while maintaining workability and production economy. Cor-Tuf can be broadly characterized as a reactive powder concrete, which is composed of fine aggregates and pozzolanic powders, but does not include coarse aggregates like those found in conventional concrete. The mixture proportion for Cor-Tuf is in table 1 .

Table 1: $\quad$ Cor-Tuf mixture composition.

\begin{tabular}{|c|c|c|}
\hline Material & Product & Proportion by weight \\
\hline Cement & Lafarge, Class H, Joppa, MO & 1.00 \\
\hline Sand & US Silica, F55, Ottawa, IL & 0.967 \\
\hline Silica flour & US Silica, Sil-co-Sil 75, Berkeley Springs, WV & 0.277 \\
\hline Silica fume & Elkem, ES $900 \mathrm{~W}$ & 0.389 \\
\hline Superplasticizer & W.R. Grace, ADVA 170 & 0.0171 \\
\hline Water (tap) & Vicksburg, MS municipal water & 0.208 \\
\hline Steel fibers ${ }^{1}$ & Bekaert, Dramix ${ }^{\circledR}$ ZP305 & 0.310 \\
\hline
\end{tabular}

For comparative purposes, two preparations of Cor-Tuf were produced for this study, i.e., Cor-Tuf1 contained steel fibers, and Cor-Tuf2 did not. The steel fibers in Cor-Tuf1 were a Dramix ${ }^{\circledR}$ ZP305 product from Bekaert Corporation. Personnel with the GSL Impact and Explosion Effects Branch conducted mechanical property tests for both preparations of Cor-Tuf. The test specimens were cut to the correct length, and the ends were ground flat and parallel to each other and perpendicular to the sides of the core in accordance with procedures in ASTM D 4543 [1]. The prepared test specimens had a nominal height of $110 \mathrm{~mm}$ and a diameter of $50 \mathrm{~mm}$. A total of 23 successful quasi-static mechanical property tests were conducted on Cor-Tuf1 and on Cor-Tuf2. The mechanical property tests consisted of hydrostatic compression (HC), unconfined compression (UC), triaxial compression (TXC), unconfined direct pull (DP), uniaxial strain (UX), and uniaxial-strain-load/constant-volume-load (UX/CV) tests. Table 2 contains the average values of wet density, water content, dry density, and air voids content from each preparation of Cor-Tuf.

Table 2: $\quad$ Average composition properties for test specimens.

\begin{tabular}{|c|c|c|c|c|}
\hline $\begin{array}{c}\text { Cor-Tuf } \\
\text { Mix }\end{array}$ & $\begin{array}{c}\text { Wet Density } \\
\mathrm{Mg} / \mathrm{m}^{3}\end{array}$ & Water Content, \% & $\begin{array}{c}\text { Dry Density, } \\
\mathrm{Mg} / \mathrm{m}^{3}\end{array}$ & $\begin{array}{c}\text { Air Voids Content, } \\
\%\end{array}$ \\
\hline 1 & 2.557 & 2.73 & 2.490 & 8.3 \\
\hline 2 & 2.328 & 3.24 & 2.256 & 11.3 \\
\hline
\end{tabular}




\section{Mechanical property tests}

All of the mechanical property tests were conducted with axial strain rates on the order of $10^{-4}$ to $10^{-5}$ per second and times to peak load on the order of 5 to 30 minutes. Undrained isotropic compressibility data were obtained during the hydrostatic loading phases of the TXC tests and from HC tests. Shear and failure data were obtained from UC tests, unconsolidated-undrained TXC tests, and DP tests. One-dimensional compressibility data were obtained from undrained UX tests with lateral stress measurements. One type of undrained strain path test was conducted during the test program. The strain path tests were initially loaded under uniaxial strain boundary conditions to a prescribed level of stress or strain. At the end of the UX loading, a constant axial-to-radial-strain ratio (ARSR) of -2.0 was applied. The ARSR $=-2.0$ path is a constant-volume-strain-loading path; these tests will be referred to as $\mathrm{UX} / \mathrm{CV}$ tests. The term unconsolidated undrained signifies that no pore fluid (liquid or gas) was allowed to escape or drain from the membrane-enclosed specimens.

\subsection{Test devices and instrumentation}

Three sets of test devices were used in this test program. The axial load for all of the UC tests was provided by a $3.3 \mathrm{MN}$ loader. The application of load was manually controlled with this test device. No pressure vessel was required for the UC tests; only a specimen base and top cap, load cell, and vertical and radial deformeters were necessary.

DP tests were performed using end caps that were attached to the unconfined specimens with a high-modulus, high-strength epoxy. A manual hydraulic pump was used to pressurize a chamber, which then retracted a piston and produced tensile loading in the test specimen. Measurements for the loading of the specimen were recorded by the load cell.

All of the remaining tests were conducted in a $600-\mathrm{MPa}$-capacity pressure vessel, and the axial load was provided by an 8.9-MN loader. With the 8.9-MN loader and associated hydraulic pump, the application of load, pressure, and axial displacement were regulated by a servo-controlled data acquisition system. This servo-controlled system allowed the user to program rates of load, pressure, and axial displacement in order to achieve the desired stress or strain path. Confining pressure was measured externally to the pressure vessel by a pressure transducer mounted in the confining fluid line. A load cell mounted in the base of the specimen pedestal was used to measure the applied axial loads.

The vertical deflection measurement system consisted of two linear variable differential transformers (LVDTs) mounted vertically inside the pressure vessel on an instrumentation stand and positioned 180-degrees apart. They were oriented to measure the displacement between the top and base caps, thus providing a measure of the axial deformations of the specimen. In addition, a linear potentiometer was mounted externally to the pressure vessel, so as to measure the displacement of the piston through which axial load was applied. This provided a backup to the internal LVDTs in case they exceeded their 
calibrated range. Two radial deflection measurement systems were used in this test program. One lateral deformeter consisted of an LVDT mounted on a hinged ring; the LVDT measured the expansion or contraction of the ring [2]. This lateral deformeter was used for smaller ranges of radial deformation when the greatest measurement accuracy was required. The second lateral deformeter consisted of two strain-gaged spring-steel arms mounted on a double-hinged ring; the strain-gaged arms deflect as the ring expands or contracts. This lateral deformeter was used when the greatest radial deformation range was required, and therefore, it is less accurate than the LVDT.

\section{Comparisons of test results}

Measurements of posttest water content for each test specimen were conducted in accordance with procedures given in ASTM D 2216 [1]. Based on the appropriate values of posttest water content, wet density, and grain density, values of dry density and air voids content of the test specimens were determined.

\subsection{Hydrostatic compression test results}

Undrained bulk compressibility data were obtained from the $\mathrm{HC}$ tests and during the hydrostatic loading phase of the TXC tests. The pressure-volume data from the $\mathrm{HC}$ tests conducted on each concrete are compared in fig. 1. The figure legend identifies the test number, and the second number designates whether the test specimen is Cor-Tuf1 or Cor-Tuf2. The initial dry densities of Cor-Tuf1 HC test specimens were 2.510 and $2.523 \mathrm{Mg} / \mathrm{m}^{3}$, while the initial dry densities of Cor-Tuf2 HC test specimens were 2.286 and $2.312 \mathrm{Mg} / \mathrm{m}^{3}$. The test specimens for each material with the lower densities (test 3-1 for Cor-Tuf1 and test 3-2 for Cor-Tuf2) were more compressible than the test specimens with the higher densities. The HC compressibility for Cor-Tufl and 2 are very similar, with Cor-Tuf2 displaying a slightly greater compressibility. This implies that the steel fibers in Cor-Tuf1 slightly reduced its compressibility compared with that of Cor-Tuf2. During the transition from loading to unloading, the pressure was held constant, and the deformations were monitored. When the deformation rate decreased significantly, the pressure was decreased. Specimens of both concretes displayed increases in the volumetric strains during the transition, which is an indication that the concretes are susceptible to creep. Based on the data from the $\mathrm{HC}$ tests, the initial elastic bulk modulus for Cor-Tufl is $25.2 \mathrm{GPa}$ and is 22.7 GPa for Cor-Tuf2.

\subsection{Triaxial compression test results}

Compression shear and failure data were successfully obtained from results of the UC tests and the unconsolidated-undrained TXC tests. The UC tests were performed in accordance with ASTM C 39 [1] and are a type of TXC test without the application of confining pressure. No attempt was made to capture the post-peak (or softening) stress-strain behavior during the UC tests. Fig. 2 
presents plots of the stress-strain data (principal stress difference versus axial strain) from the UC tests for each concrete. The UC test results are very sensitive to small changes in the dry density and specimen structure, which cause variations of the initial loadings and peak strengths. The mean unconfined compressive strengths of Cor-Tuf1 and Cor-Tuf2 were 237 and $210 \mathrm{MPa}$, respectively.

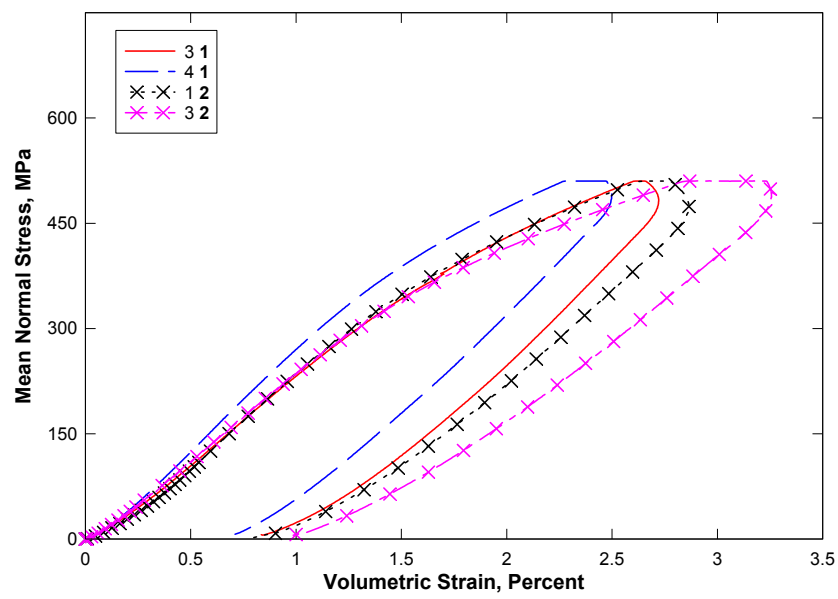

Figure 1: $\quad$ Pressure-volume responses from $\mathrm{HC}$ tests.

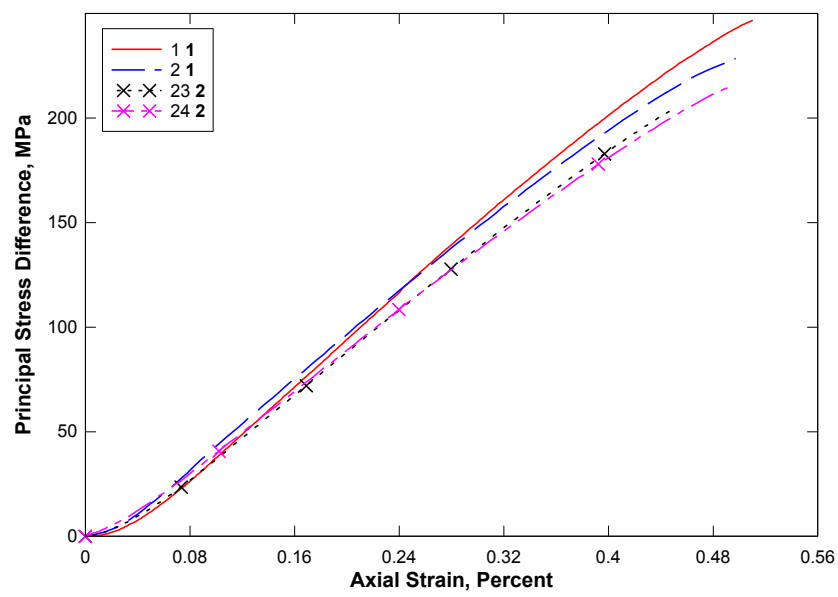

Figure 2: $\quad$ Stress-strain data from UC tests.

For comparison purposes, stress-strain data from selected TXC tests conducted with constant confining pressures of 10, 20 and $50 \mathrm{MPa}$ are plotted in fig. 3, while stress-strain data from selected TXC tests with constant confining 
pressures of 100, 200, and $300 \mathrm{MPa}$ are plotted in fig. 4. The legend for symbols in these two figures includes the test number, the level of confining pressure, and the number label for Cor-Tuf. For plotting purposes, the axial and volumetric strains at the beginning of the shear phase were set to zero, i.e., only the strains during shear are plotted. A few comments should be made concerning the unloading results. The final unloading stress-strain responses at axial strains approaching 15 percent are less reliable than the unloadings at axial strains of less than 11 percent. The internal vertical deformeters go out of range at axial strains of approximately 11 percent. After that, an external deformeter with less resolution is used to measure axial displacement.

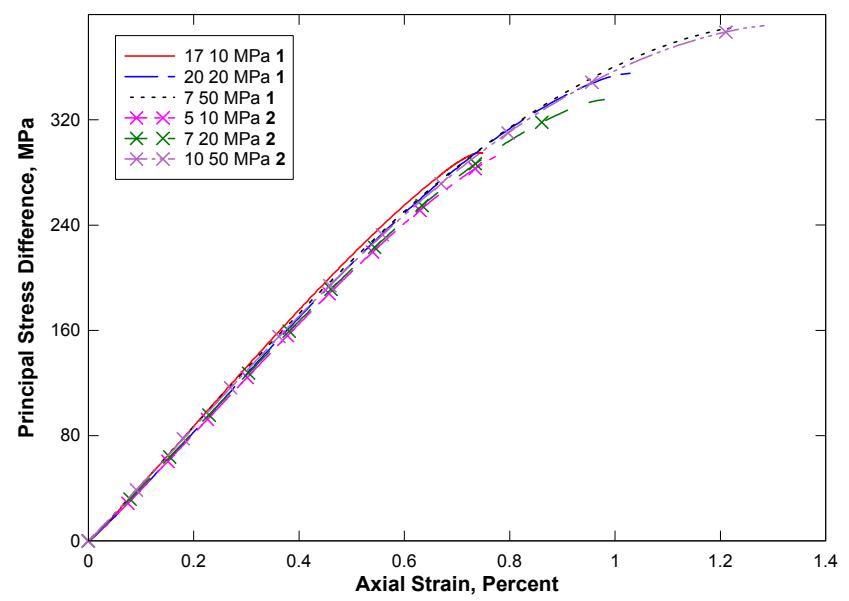

Figure 3: $\quad$ Stress-strain data from selected TXC tests at constant confining pressures between 10 and $50 \mathrm{MPa}$ from Cor-Tuf1 and Cor-Tuf2.

The peak strengths of the test specimens for Cor-Tuf1 and 2 are very similar for confining pressures between 10 and $50 \mathrm{MPa}$ (fig. 3). Cor-Tuf1 clearly displays increases in strength over Cor-Tuf2 with confining pressures of $100 \mathrm{MPa}$ and greater (fig. 4). The increased strength of Cor-Tuf1 is a result of the steel fibers and the density of the test specimens.

Fig. 4 illustrates both the brittle and ductile nature of Cor-Tuf1 and Cor-Tuf2. At confining pressures of $100 \mathrm{MPa}$ and below, Cor-Tuf1 and Cor-Tuf2 test specimens behave in a brittle manner, i.e., the material strain-softens. At confining pressures above $100 \mathrm{MPa}$, Cor-Tuf1 and Cor-Tuf2 behave in a ductile manner, i.e., the stress-strain data exhibit strain hardening. The initial compaction then dilation during shear is displayed in the volumetric strain responses (fig. 5) for Cor-Tufl and 2 at confining pressures of $100 \mathrm{MPa}$ and above.

The failure data and the compression failure surfaces for both concretes developed from the UC and TXC test results are plotted in fig. 6 as principal stress difference versus mean normal stress. The recommended failure surfaces for Cor-Tuf1 and Cor-Tuf2 are initially the same. However, as the confining 


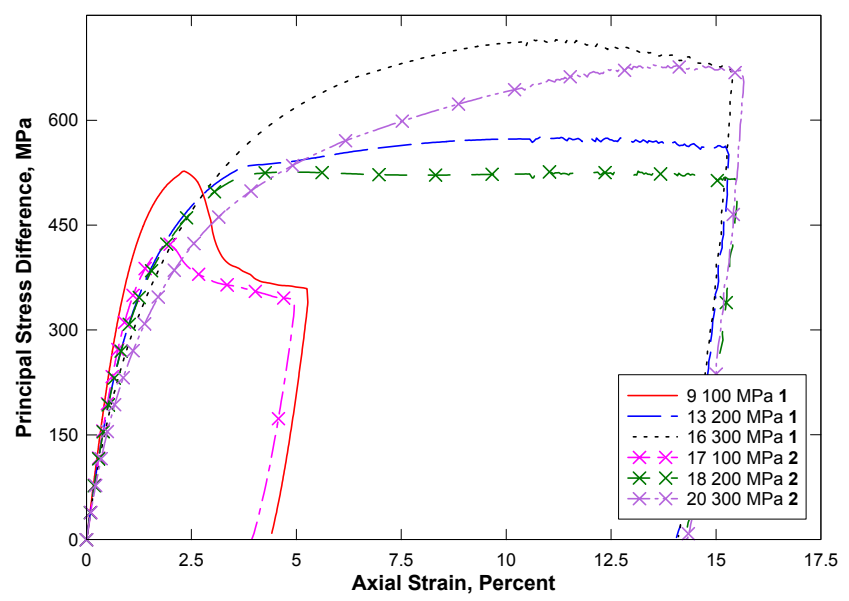

Figure 4: $\quad$ Stress-strain data from selected TXC tests at constant confining pressures between 100 and $300 \mathrm{MPa}$ from Cor-Tuf1 and Cor-Tuf2.

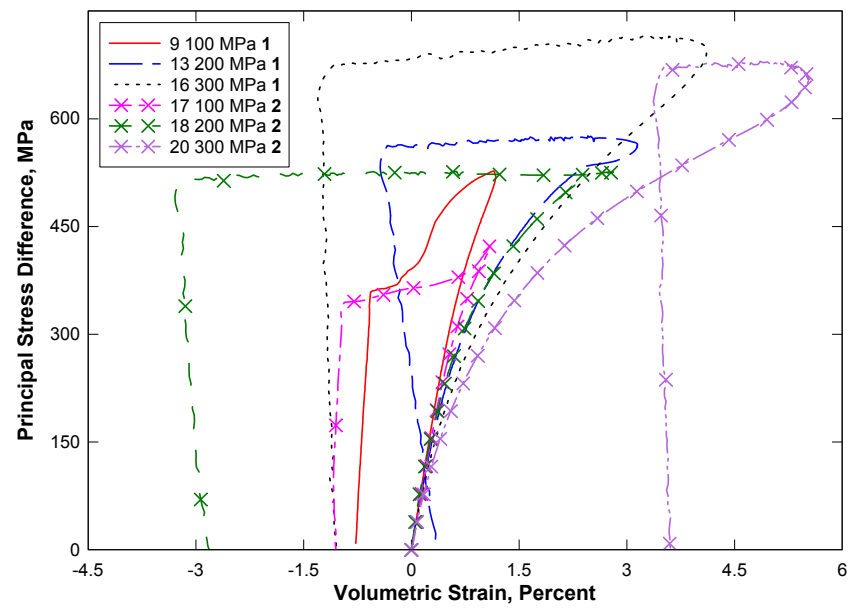

Figure 5: Stress difference-volumetric strain responses during shear from selected TXC tests at confining pressures between 100 and $300 \mathrm{MPa}$ from Cor-Tuf1 and Cor-Tuf2 concrete.

pressure increases, the failure surface for Cor-Tuf1 becomes slightly greater than the failure surface for Cor-Tuf2. The response data from the $300 \mathrm{MPa}$ TXC tests indicate that both Cor-Tuf1 and Cor-Tuf2 have not reached void closure. Concrete materials can continue to gain strength with increasing pressure until all of the air porosity in the specimen is crushed out, i.e., when void closure is tests and under hydrostatic loading conditions. The failure surface will have a minimal slope after void closure is achieved. 


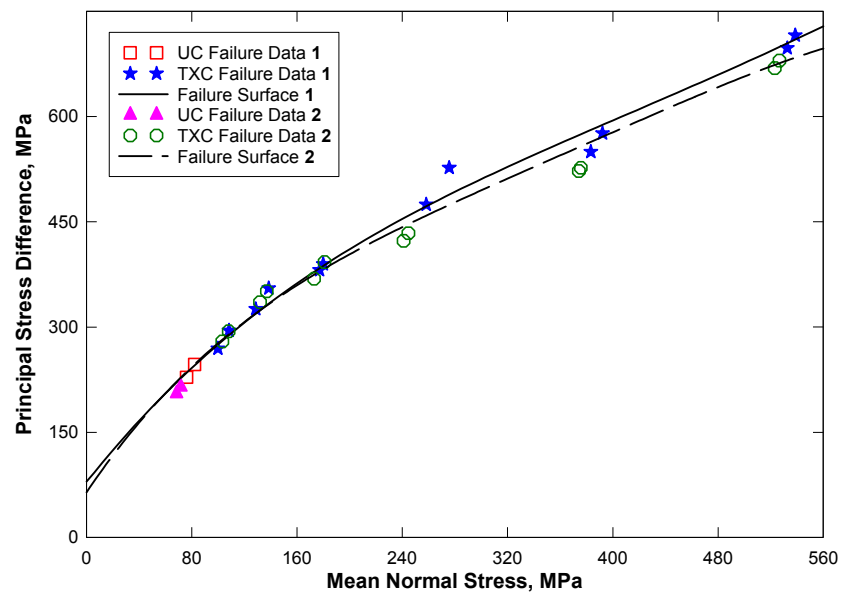

Figure 6: $\quad$ Failure data from UC and TXC tests and the failure surfaces for both materials.

\subsection{Direct pull test results}

Results from the DP tests are plotted in fig. 7. The average tensile strength from the Cor-Tuf1 DP tests was at $-5.58 \mathrm{MPa}$, while the Cor-Tuf2 DP test specimen failed at $-8.88 \mathrm{MPa}$. There was only one test completed for Cor-Tuf2, because the high strength epoxy failed in two tests before the test specimens fractured. The average tensile strength of Cor-Tufl concrete is $2.4 \%$ of its average unconfined compression strength, while the tensile strength of the Cor-Tuf2 concrete is $4.2 \%$ of its average unconfined compression strength. According to ACI 318-02 [3], the tensile strength of concrete is normally assumed to be about 10 to $15 \%$ of the compressive strength. In this case, both Cor-Tufl and 2 have less tensile strength than generally assumed by ACI 318-02.

\subsection{Uniaxial strain test results}

Comparisons of the UX test results for the two concretes are in figs. 8 and 9. The stress-strain data are plotted in fig. 8 and the stress paths with the TXC failure surfaces in fig. 9. Cor-Tuf2 displays greater amounts of axial strain (fig. 8) than Cor-Tuf1; therefore, Cor-Tuf2 compresses more than Cor-Tuf1. The steel fibers and the densities of the Cor-Tuf1 test specimens reduce the compressibility of the test specimens.

From the UX stress-strain loading data in fig. 8, the initial constrained modulus of Cor-Tuf1 is $47.4 \mathrm{GPa}$, while the initial constrained modulus of Cor-Tuf2 is $43.1 \mathrm{GPa}$. An initial shear modulus of $16.7 \mathrm{GPa}$ was calculated for Cor-Tufl concrete and 15.3 GPa for Cor-Tuf2 concrete based on each concretes' initial constrained modulus and bulk modulus (25.2 GPa for Cor-Tufl concrete and 22.7 GPa for Cor-Tuf2 concrete) determined from the HC tests. Any two moduli may be used to calculate any of the other elastic constants, e.g., Young's 


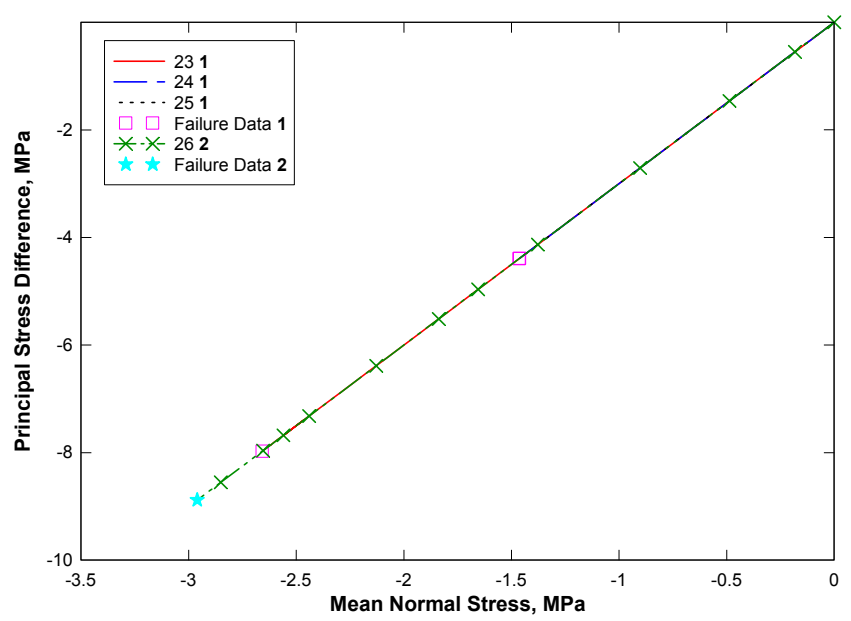

Figure 7: $\quad$ Stress paths from DP tests and the failure data for Cor-Tufl and Cor-Tuf2.

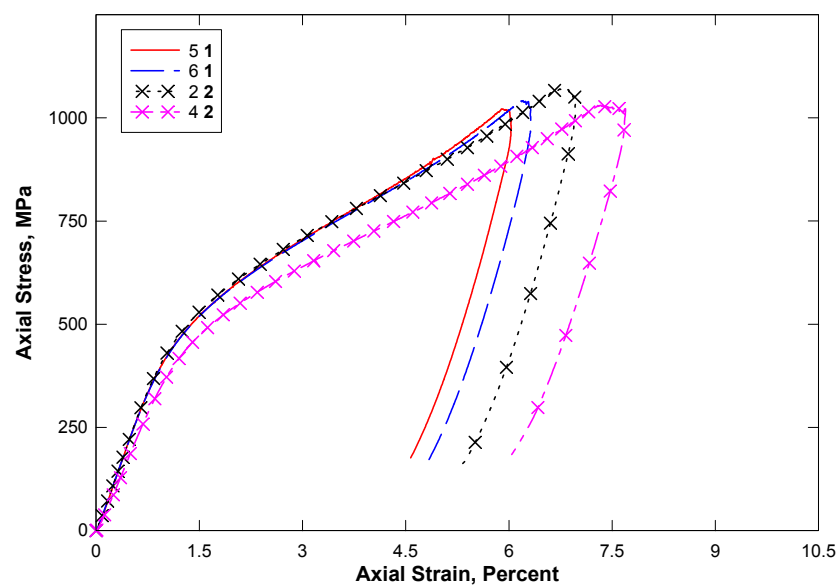

Figure 8: $\quad$ Stress-strain responses from UX tests.

modulus and Poisson's ratio. The initial Young's modulus for Cor-Tuf1 is 40.9 GPa and 37.5 GPa for Cor-Tuf2 concrete. The initial Poisson's ratio is 0.23 for Cor-Tuf1 and 0.22 for Cor-Tuf 2 concrete.

The stress paths for both concretes (fig. 9) are very similar; both concretes experience crushing of the cement bonds at approximately $300 \mathrm{MPa}$, and neither display full saturation. 


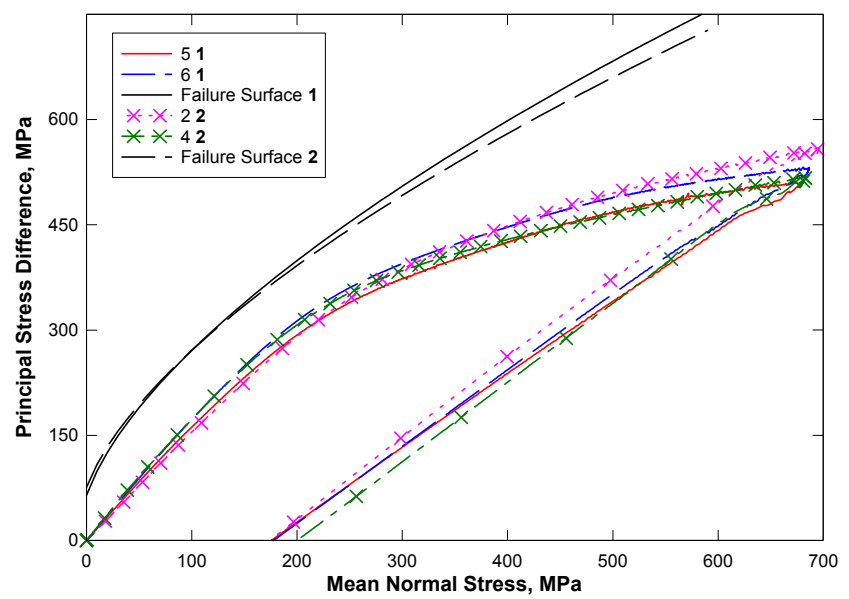

Figure 9: $\quad$ Stress paths from UX tests and the TXC failure surfaces for CorTuf1 and Cor-Tuf2.

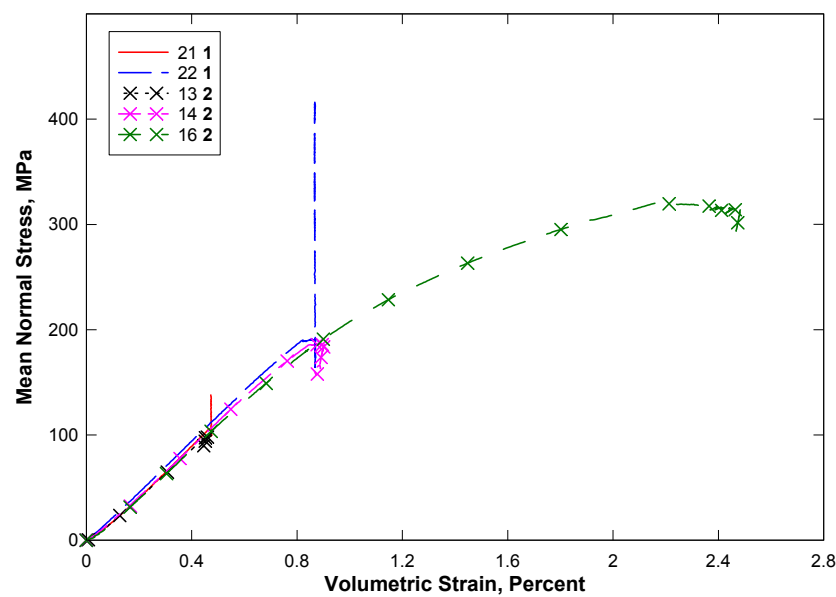

Figure 10: Pressure-volume data from the UX/CV tests for Cor-Tuf1 and Cor-Tuf2.

\subsection{Strain path test results}

One type of special strain path test was conducted. UX/CV refers to tests with uniaxial strain loading followed by constant volumetric strain loading $($ ARSR $=-2.0)$. The UX/CV tests were loaded in UX to peak axial stresses of about 50 and $100 \mathrm{MPa}$ for both materials. One Cor-Tuf2 test was loaded to $200 \mathrm{MPa}$ in UX. Comparisons of the results of UX/CV strain-path tests conducted on the two concretes are shown in figs. 10 and 11. The pressure- 
volume data are in fig. 10 and the stress-paths with the failure surface data are in fig. 11. Mechanical problems occurred during the CV portion of all the tests performed on Cor-Tuf2. The pressure volume data for Cor-Tuf1 (fig. 10) shows that the specimens were held at a constant volume. Cor-Tuf1 test specimen 22 and Cor-Tuf 2 test specimen 14 displayed similar results until test specimen 14 was concluded because of a mechanical problem during the test.

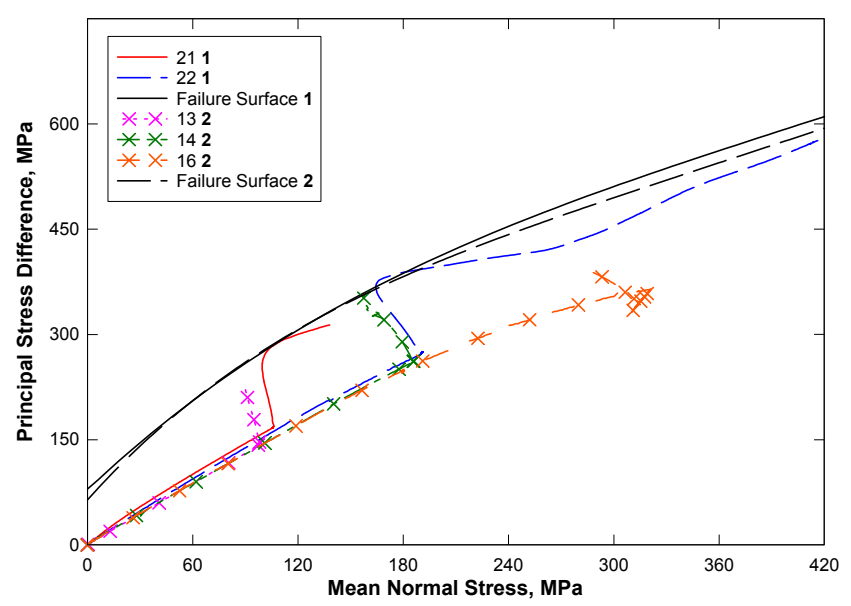

Figure 11: Stress paths from UX/CV tests and TXC failure surfaces for CorTuf1 and Cor-Tuf2.

\section{Conclusions}

Personnel in the GSL, ERDC conducted a series of laboratory experiments to investigate the strength and constitutive property behavior of baseline ultra-highperformance composite (Cor-Tuf) concrete with and without steel fibers. A total of 23 successful mechanical property tests were conducted for each material.

The overall quality of the test data was very good. Cor-Tuf1 and Cor-Tuf2 concrete behave similarly, but Cor-Tuf1 exhibits greater strength with increased confining pressure, and Cor-Tuf2 displays greater compressibility. For both materials, creep was observed during the $\mathrm{HC}$ tests. Results from the TXC tests exhibited a continuous increase in principal stress difference with increasing confining stress. A compression failure surface was developed from results of TXC and UC tests. The results for the DP tests were used to determine the tensile strength of the concretes. By comparing the unconfined compression and unconfined tensile strengths, it is apparent that both concretes' tensile strengths are less than $10 \%$ of their unconfined compression strengths. The CV loading for Cor-Tuf1 followed closely along the TXC failure surface, which validates the failure surface. Overall, the results from all of the compression tests for the Cor-Tuf concretes were very similar. More tensile dominant tests are required to demonstrate the effects of the steel fibers in Cor-Tuf. 


\section{Acknowledgement}

The tests described and the resulting data presented herein were obtained from research conducted jointly under the Scalable Technology for Adaptive Response and Defeat of Emerging Adaptive Threats Work Packages of the U.S. Army Corps of Engineers, Engineer Research and Development Center, 3909 Halls Ferry Road, Vicksburg, MS 39180-6199. Permission to publish this paper was granted by the Director, Geotechnical and Structures Laboratory.

\section{References}

[1] American Society for Testing and Materials, Annual book of ASTM standards, ASTM, Philadelphia, PA. 2005. Designation C 39-05. Standard test method for compressive strength of cylindrical concrete specimens. Designation D 2216-05. Standard test method for laboratory determination of water (moisture) content of soil and rock by mass. Designation D 454304. Standard practices for preparing rock core as cylindrical test specimens and verifying conformance to dimensional and shape tolerances.

[2] Bishop, A.W., \& Henkel, D.J., The Measurement of Soil Properties in the Triaxial Test, Edward Arnold, LTD, London, 1962.

[3] ACI 318R-02. Building Code Requirements for Structural Concrete and Commentary. ACI Committee Report 318. American Concrete Institute, Detroit, 318R10.2.5, 2002. 